\title{
PODER LOCAL, HEGEMONIA E DISPUTA: OS CONSELHOS MUNICIPAIS EM PEQUENOS MUNICÍPIOS DO INTERIOR
}

\author{
Osmir Dombrowski
}

\begin{abstract}
RESUMO
O artigo aborda a instituição dos conselhos municipais em pequenos municípios do interior, que somam mais da metade do total de municípios do país. A hipótese é que os pequenos municípios podem funcionar como verdadeiros "microscópios", revelando fenômenos que, apesar de universais, tendem a perder-se na complexidade das relações políticas nas grandes cidades. O trabalho estrutura-se em duas seções. $\mathrm{Na}$ primeira é feito um rápido comentário sobre o processo de consolidação e disseminação de um preconceito que acompanha os estudos do Brasil rural e atinge a análise do poder local; argumentamos que a teoria não pode reservar para os pequenos municípios do interior apenas o papel de redutos do atraso, da falta de consciência cívica e do baixo desenvolvimento da cultura política democrática. Na segunda parte apresentam-se alguns dados empíricos levantados em pesquisa junto aos conselhos na região Oeste do estado do Paraná, os quais sugerem que, apesar de evidentes limitações, essas instituições podem funcionar como uma via alternativa de acesso a recursos políticos, tornando-se, por isso, palco de disputas: é o teor dessa disputa que, em última instância, determina a inconstância característica do desempenho dos conselhos em diferentes locais.
\end{abstract}

PALAVRAS-CHAVE: poder local; conselhos municipais; clientelismo; participação.

\section{INTRODUÇÃO: INDICAÇÕES PARAA PES- QUISA EM PEQUENOS MUNICÍPIOS DO IN- TERIOR}

Já se tornou comum a referência aos conselhos municipais como uma das grandes novidades do cenário político brasileiro das últimas décadas. Sem negar que tais instituições podem caminhar para uma nova forma de relacionamento entre Estado e sociedade - tanto na direção do empowerment das comunidades e grupos sociais locais e da governança democrática das políticas públicas, quanto da cooptação e da desmobilização dos setores populares -, é possível acompanhar uma sugestão de Celina Souza, para quem "o novo sistema de governança local materializa-se de forma desigual entre os municípios brasileiros e sua sustentabilidade ainda não está clara” (SOUZA, 2004).
Pode parecer um tanto óbvio, mas é absolutamente necessário repetir aqui o mote, tantas vezes batido, de que em um país com dimensões continentais como o Brasil é bastante lógico supor que um mesmo fenômeno possa apresentar características diferentes dependendo da região em que se manifeste. Destaca-se que tais diferenças podem ser ainda mais acentuadas entre municípios de regiões metropolitanas e "não-metropolitanas", por nós chamados de "pequenos municípios do interior". Assim, se os conselhos municipais constituem-se em uma novidade institucional importante, mas que se manifestam de maneira desigual, é interessante que a análise considere a dimensão populacional, que talvez seja uma das mais imediatas expressões da desigualdade entre os municípios no Brasil, como se pode ver nas tabelas 1 e 2 a seguir: 
TABELA 1 - POPULAÇÃO POR CLASSE DE TAMANHO DA POPULAÇÃO DOS MUNICÍPIOS

\begin{tabular}{|l|c|c|}
\hline CLASSE DE TAMANHO DA POPULAÇÃO DOS MUNICÍPIOS & POPULAÇÃO & 㗱 \\
\hline Até 5000 & 4606246 & 3 \\
De 5001 a 20000 & 28994620 & 17 \\
De 20001 a 100000 & 49707668 & 29 \\
De 100001 a 500000 & 39755647 & 23 \\
Mais de 500000 & 46808675 & 28 \\
Total & 169872856 & 100 \\
\hline
\end{tabular}

FONTE: o autor, a partir de IBGE (2004a).

TABELA 2 - QUANTIDADE DE MUNICÍPIO POR CLASSE DE TAMANHO DA POPULAÇÃO DOS MUNICÍPIOS

\begin{tabular}{|l|c|c|}
\hline \multicolumn{1}{|c|}{ CLASSES DE TAMANHO DOS MUNICÍPIOS } & QUANTIDADE DE MUNICÍPIOS & \% \\
\hline Até 5000 & 1359 & 24 \\
De 5001 a 20000 & 2631 & 47 \\
De 20001 a 100000 & 1317 & 24 \\
De 100001 a 500000 & 219 & 4 \\
Mais de 500000 & 34 & 1 \\
Total & 5560 & 100 \\
\hline
\end{tabular}

FONTE: o autor, a partir de IBGE (2004b).

Um rápido olhar nas tabelas acima informanos que simplesmente $95 \%$ dos municípios brasileiros, ou seja, 5307 de um total de 5 560, possuem menos de 100 mil habitantes e que esses mesmos municípios abrigam quase a metade $-49 \%$ da população do país. Isso implica dizer que se os conselhos municipais constituem uma inovação importante na política e na organização institucional brasileiras, eles devem ter sua dinâmica e seu funcionamento analisados também nesses pequenos municípios, caso contrário estar-se-á excluindo a absoluta maioria das instituições e com elas a metade da população do país. Em sentido semelhante, Ana Cláudia Teixeira (2006) chama a atenção para a importância do estudo das novas instituições em pequenos municípios quando pensamos nas possibilidades de replicação da experiência.

É ainda Celina Souza no artigo anteriormente citado quem tem o mérito de remeter-nos ao centro do problema. Segundo ela, existe um tipo específico de conselho, “[...] não incomum nas comunidades pequenas e pobres, em que muitas vezes os membros do conselho são indicados pelos dirigentes locais, principalmente o Prefeito, e o seu papel é o de ratificar as decisões tomadas pelo [poder] Executivo local" (SOUZA, 2004, p. 39). A autora expõe, portanto, a fragilidade dessas novas instituições, questionando a legitimida- de de seus integrantes, ao mesmo tempo em que evidencia a concentração do poder na alçada do poder Executivo, que permanece na política brasileira apesar dos impulsos participativos e descentralizadores que atuaram na elaboração da Constituição de 1988. Essas razões, entretanto, não podem levar à conclusão, apressada, de que nos pequenos municípios do interior os limites que se colocam ao potencial dos conselhos municipais de constituírem instrumentos de promoção de uma "governança democrática" são maiores e/ ou mais sólidos que aqueles encontrados nas regiões metropolitanas ou nas áreas industrializadas. Como alternativa, aventamos a hipótese de que a análise em pequenos municípios pode revelar elementos que, ainda que sejam universais, são pouco evidentes nas regiões metropolitanas. Pensamos que o pequeno município pode funcionar para a análise sociopolítica como uma espécie de microscópio, capaz de permitir-nos a observação de elementos que se perdem quando soltos na imensidão das metrópoles, mas que são universais, quer dizer, que têm validade para pensar-se a organização democrática da sociedade brasileira como um todo.

Nesse sentido, apresentamos a seguir algumas reflexões em duas seções distintas. Na primeira é feita uma rápida discussão sobre o processo de consolidação e disseminação de certo preconcei- 
to que acompanha os estudos do poder local no Brasil rural e atinge a análise dos pequenos municípios do interior; na segunda, apresentamos e discutimos alguns dados empíricos levantados por nossa pesquisa sobre os conselhos municipais na região Oeste do estado do Paraná1.

\section{NOTAS PARA O ESTUDO DO PODER LO- CAL NO BRASIL RURAL}

Durante muito tempo, o "local” na política brasileira foi tido como lócus dos desmandos autoritários de mandatários das elites locais ou regionais. A idéia subentendida nesse adágio é que, fazendo uso de recursos econômicos, a elite local domina e submete o aparelho de Estado aos seus desígnios particulares, afastando todos os outros segmentos, notadamente os setores populares. Daí ser o poder local perdulário, mal gastador do dinheiro público, quase sempre corrupto e que tem a ineficiência como sua marca característica. Pela mesma razão o poder local foi também, durante muito tempo, considerado instrumento do "atraso”. Ou seja, trata-se de uma instância de governo que, em vez de promover o progresso e o desenvolvimento, trabalha no sentido de contê-lo, de impedir que ocorra. Aqui a idéia subentendida é a de que o desenvolvimento poderia alterar a correlação de força no interior da sociedade em detrimento dessa elite que, por isso mesmo, trabalha no sentido de contê-lo como forma de manutenção do status quo.

É necessário observar que essa construção foi responsável por difundir entre nós uma aversão extremada às instâncias locais de governo. Explica-se: praticamente toda reflexão política e social do Brasil das décadas de 1920 e 1930 fazia - como não podia deixar de ser - uma crítica profunda e rigorosa da descentralização republicana que abandonara o país ao apetite das oligarquias locais e regionais de base rural. A fragmentação do povo, disperso em imensas unidades rurais, foi considerada um obstáculo até mesmo para a realização da idéia de nação entre os brasileiros. Assim debilitado, dizia Nestor Duarte (1966), o Estado não conseguiu sobrepor-se ao poder privado. A ideologia centralizadora que emergiu no processo da

1 Trata-se de um trabalho levado a termo pelo Grupo de Pesquisa em Democracia e Desenvolvimento da Universidade Estadual do Oeste do Paraná (Unioeste) que têm como um dos seus objetivos a montagem de um amplo banco de dados sobre os conselhos municipais da região.
Revolução de 1930, ao mesmo tempo em que guardava muitos pontos de proximidade com as idéias fascistas que ganhavam a consciência de grande parte do povo europeu, era em larga medida a negação do liberalismo oligárquico que embasava a república. A mais bem acabada justificativa do centralismo entre nós talvez seja a de Oliveira Vianna: “O erro fundamental dos nossos constitucionalistas tem sido dar à autonomia local um conteúdo maior do que é aconselhável em nosso meio, um conteúdo demasiadamente amplo - ou porque anglo-saxônico ou porque meramente teórico; conceito que não atende às nossas realidades de formação social e de estruturas cultural. Estamos, neste ponto, em contradição aberta com as indicações da ciência social e da ciência política. Estas nos dizem que no nosso conceito de autonomia local (Estados e municípios) poderemos incluir todos os direitos que quisermos, menos um: - o direito às autoridades que têm o encargo da defesa das liberdades civis. Estas devem trazer o carisma de uma autoridade mais alta e mais imparcial - que não pode ser outra senão a da Nação" (OLIVEIRA VIANNA, 1987, p. 157; grifos no original).

Na prática, a centralização proposta no bojo da Revolução de 1930 significava esvaziar as instâncias locais de poder, transferindo-o para o governo central, ao mesmo tempo em que se procurava "blindar" (para usar um neologismo da moda) o governo central contra as pressões locais ou localistas.

O que se passou nos anos seguintes foi a consolidação da hegemonia da ideologia desenvolvimentista que, para firmar-se, teve que enfrentar, e derrotar, o pensamento econômico de cunho liberal (BIELSCHOWSKY, 1995). Essa vitória correspondeu na esfera política à imposição da dominação dos setores urbanos e industriais apoiados no poder do Estado e legitimado pelas massas populares sobre a antiga oligarquia rural. Nesse processo de conquista da hegemonia no plano das idéias e de imposição da dominação no terreno da política, o país aparece dividido em dois: o país do progresso e o país do atraso. $\mathrm{O}$ primeiro, urbano e industrial, ligado ao futuro e ao mundo moderno; o outro, rural e agrícola, ligado ao passado, a um mundo supostamente feudal porque dominado pelos grandes proprietários de terra. O poder do central, condutor do processo de modernização, sediado na capital, aparece 
ligado ao Primeiro Mundo, e os poderes locais, sediados no interior, aparecerão, definitivamente, ligados ao atraso do mundo rural e oligárquico: este é o mundo dos desmandos autoritários, dos resíduos feudais, do clientelismo e do coronelismo.

Pouco importa dizer que Victor Nunes Leal foi mal interpretado ${ }^{2}$, que o coronelismo não era para esse autor expressão de alguma hipertrofia do poder local mas, pelo contrário, expressava sua submissão ao poder central. Na construção ideológica desenvolvimentista, "coronelismo", "clientelismo" e "assistencialismo" foram compreendidos como diferentes expressões do atraso do mundo rural e oligárquico que deveria ceder lugar para o desenvolvimento por intermédio de um processo de industrialização, planejado e conduzido pelo Estado. O planejamento central e a ação diretiva e coordenadora do Estado constituíramse assim nos principais instrumentos preconizados para a promoção do processo de modernização. Isso acabou consumando a completa submissão das esferas locais de governo ao poder central. O local é completamente destituído de autonomia para agir apenas no sentido previsto pelo planejamento central.

O desenvolvimentismo tornou-se uma das ideologias mais sólidas e duradouras da nossa história republicana. Mesmo que suas versões cepalina e isebiana tenham sido duramente criticadas ainda em meados dos anos 1960, traços de desenvolvimentismo continuaram visíveis tanto nas políticas econômicas dos governos militares quanto no discurso das oposições. A divergência, em muitos momentos, dava-se mais sobre os meios do que sobre os fins, permanecendo uma espécie de consenso tácito em torno da idéia de que o desenvolvimento (no sentido ideológico de desenvolvimento capitalista industrial) deveria ser a principal meta dos governos. Vinte anos de ditadura, entretanto, contribuíram fortemente para o questionamento da centralização; com a queda do regime militar, a descentralização e a participação da sociedade civil foram recolocadas como princípios inerentes ao processo democrático. As esferas locais de governo começaram a ser vistas como lócus da participação. Ganhou força naquele processo a idéia de que os indivíduos vivem nos municípios e não nos estados ou na federa-

2 Sobre os problemas na interpretação do conceito elaborado por Leal, ver Carvalho (1995). ção e que, portanto, aqueles constituem-se em instâncias privilegiadas para a atuação política do cidadão. Também se dirá que o cidadão reúne mais condições de participar no nível municipal, ou local, porque é neste nível que são tratadas aquelas coisas que lhes dizem respeito diretamente: asfalto, transporte, escola, posto de saúde etc. Além do preconceito expresso nessa fórmula que toma o cidadão comum como incapaz de opinar sobre as "grandes questões nacionais" e, talvez em decorrência disso, um dos problemas verificados naquele processo é que a descentralização ocorreu sem que os municípios tenham adquirido autonomia do ponto de vista orçamentário. Ou seja, enquanto os cidadãos são chamados a participar dos processos decisórios, aos municípios não são dadas condições de atender as suas demandas, pois a maioria dos pequenos municípios não apresenta atividade econômica capaz de gerar uma arrecadação tributária suficiente e conta com repasses estaduais e federais (basicamente do Imposto sobre Circulação de Mercadorias e Serviços (ICMS) e do Fundo de Participação de Municípios (FPM)) para custear suas atividades.

Ocorre que a idéia descentralizadora ganhou consistência no decorrer de uma agenda neoliberal de reformas do Estado - que apresenta entre seus objetivos não apenas a transferência de encargos da esfera federal para as estadual e municipal, como também a "desresponsabilização" do Estado, em todos os níveis, transferindo parte de suas obrigações para o mercado, ou para a sociedade civil. No discurso liberal, participação passa a confundir-se com solidariedade, responsabilidade social e empreendedorismo, diante de uma inevitável frustração (ou mesmo antecipando-se a ela), a justificativa para o invariavelmente baixo rendimento do sistema - no sentido de que ele não atende às demandas dos cidadãos - é que ele encontra-se capturado por posturas tradicionais; faltalhe o ânimo proporcionado pelo "espírito empreendedor ou participativo” dos cidadãos. A ausência de uma cultura política democrática ou o predomínio de uma mentalidade tradicional são quase sempre chamados como variáveis explicativas principais. Ao referir-se aos pequenos municípios do interior, esse discurso reforça o antigo preconceito desenvolvimentista, colocando-os como estruturas dominadas por elites tradicionais, précapitalistas ou pré-liberais porque oligárquicas de base rural, mesmo que do ponto de vista econômico o discurso seja obrigado a aceitar a moder- 
nização da elite agrária alçada à condição de “empreendedora do agronegócio".

É evidente que não se pode negar o exercício da dominação política dos grandes proprietários de terras e das grandes empresas agro-industriais no nível local. A modernização da agricultura operada entre os anos 1960 e 1990 não eliminou a classe proprietária de terras. O antigo coronel modernizou-se, mas continua existindo na figura do grande proprietário de terras e da grande empresa de agronegócio. $\mathrm{O}$ que se pretende neste trabalho é, pelo contrário, buscar um foco para analisar o fenômeno sem que as lentes do preconceito contra o mundo rural provoquem distorções - distorções que, por sua vez, acabam conturbando a própria análise dos mesmos fenômenos quando se manifestam no meio urbano. Assim, é preciso ficar claro que o controle exercido por esses modernos "coronéis" sobre o espaço público e a máquina estatal nos pequenos municípios do interior não é uma manifestação de "atraso", como pensavam os desenvolvimentistas; trata-se, isso sim, da mais pura expressão da hegemonia exercida pela fração agro-industrial da mesma classe capitalista que exercita a sua dominação no mundo urbano e resulta do aprofundamento das relações capitalistas. A teoria não pode, portanto, reservar para os pequenos municípios do interior apenas o papel de redutos do atraso, da falta de consciência cívica, do baixo desenvolvimento da cultura política democrática etc., pois a história tem registrado exemplos bem-sucedidos de experiências participativas em municípios do interior ${ }^{3}$. Se o desenvolvimento e a consolidação dessa "nova institucionalidade" em que se constituem os conselhos municipais apresenta-se aos analistas de modo desigual (SOUZA, 2002; 2004) é porque - de fato - o caminho da construção da democracia entre nós é, como aponta Dagnino (2002), verdadeiramente complexo e contraditório.

\section{TRAÇOS DE UMA NOVA INSTITUCIONA- LIDADE}

Nesta seção apresentaremos alguns traços do desenho institucional de um conjunto de conselhos ativos em municípios da região Oeste do estado do Paraná (Tabela 3). Fizemos, nesse ponto, a opção metodológica de abordar os conselhos a partir de elementos retirados de seus regimentos internos ou do ato jurídico (lei ou decreto municipal) de que procede a sua criação. Com isso foi possível perceber os traços que contornam seu desenho institucional, mas estamos cientes das limitações dessa abordagem, que pouco nos informa sobre o comportamento dos atores que estão (ou deveriam estar) envolvidos no processo de constituição e consolidação dessas novas instituições. Nossa pesquisa prevê para o futuro um aprofundamento nessa direção.

TABELA 3 - POPULAÇÃO E QUANTIDADE DE CONSELHOS ATIVOS POR MUNICÍPIO

\begin{tabular}{|l|c|c|}
\hline MUNIĆ́PIO & POPULAÇÃO & CONSELHOS ATNOS \\
\hline Cascavel & 245066 & 10 \\
Toledo & 98200 & 10 \\
Marechal Cândido Rondon & 41007 & 8 \\
Sẫo Miguel do lguaçu & 24432 & 8 \\
Vera Cruz do Oeste & 8574 & 8 \\
Ouro Verde do Oeste & 5472 & 8 \\
Sấo José das Palmeiras & 4102 & 6 \\
\hline
\end{tabular}

FONTE: o autor, com base em IBGE (2008).

\section{III.1. Difusão dos conselhos municipais}

Desde logo, deve-se registrar que não é tão óbvia a correlação entre o número de conselhos em um município e o seu número de habitantes. É o que se torna claro na Tabela 3. Nela observase que uma cidade com pouco mais de cinco mil habitantes apresenta o mesmo número de conselhos ativos que outras com mais de 20 ou 40 mil habitantes. Da mesma forma, Toledo, um município com cerca de 100 mil habitantes, possui o mesmo número de conselhos ativos que Casca-

\footnotetext{
3 Para o conhecimento de algumas dessas experiências veja Alves (1980) sobre a democracia participativa em Lajes (Santa Catarina) nos anos 1970 e Teixeira (2006) sobre o orçamento participativo em pequenos municípios rurais.
} 
vel, cuja população é de 245 mil habitantes. Será muito mais fácil encontrar uma explicação para a quantidade de conselhos ativos nos municípios em fatores históricos ligados à dinâmica social e à política local ou no posicionamento dos gestores municipais quanto à participação pública em suas administrações (cf., por ex., GOHN, 2001; CÔRTES, 2002; 2005), que na quantidade de ha- bitantes dos respectivos municípios.

Quando se procura saber quais são os conselhos existentes em cada município, nota-se que alguns deles estão presentes em todos os municípios analisados, outros aparecem apenas em parte deles e outros, ainda, surgem exclusivamente em um município (Quadro 1).

QUADRO 1 - RELAÇÃO DE CONSELHOS MUNICIPAIS ATIVOS NOS MUNICÍPIOS PESQUISADOS

\begin{tabular}{|c|c|c|c|c|c|c|c|}
\hline \multirow[b]{2}{*}{ CONSELHO } & \multicolumn{7}{|c|}{ MUNicípIo } \\
\hline & Cascavel & Toledo & $\begin{array}{c}\text { Mal. } \\
\text { Cândido } \\
\text { Rondon }\end{array}$ & $\begin{array}{l}\text { S. Miguel } \\
\text { do lguaçu }\end{array}$ & $\begin{array}{l}\text { Vera Cruz } \\
\text { do Oeste }\end{array}$ & $\begin{array}{c}\text { Ouro Verde } \\
\text { do Oeste }\end{array}$ & $\begin{array}{c}\text { S. José } \\
\text { das } \\
\text { Palmeiras }\end{array}$ \\
\hline Fundef & * & * & * & * & * & * & * \\
\hline Alimentação Escolar & * & * & * & * & * & * & * \\
\hline Assistência Social & * & * & * & * & * & * & * \\
\hline Saúde & * & * & * & * & * & * & * \\
\hline Direitos da Criança & * & * & * & * & * & * & * \\
\hline Segurança & * & * & * & & & * & \\
\hline $\begin{array}{l}\text { Desenvolvimento } \\
\text { Rural }\end{array}$ & * & * & * & & & & * \\
\hline $\begin{array}{l}\text { Emprego e de } \\
\text { R elapoues do } \\
\text { Trabalho }\end{array}$ & & * & & * & & * & \\
\hline Direitos do Idoso & * & & & * & * & & \\
\hline "Antidrogas" & * & & & & & & \\
\hline Trânsito & & * & * & & & & \\
\hline Meio Ambiente & * & * & & & & & \\
\hline $\begin{array}{l}\text { Agricultura e Meio } \\
\text { Ambiente }\end{array}$ & & & & & * & & \\
\hline $\begin{array}{l}\text { Desenvolvimento } \\
\text { E conômioo }\end{array}$ & & & & & * & & \\
\hline E ducaçẫo & & & & & & * & \\
\hline Turismo & & & & * & & & \\
\hline
\end{tabular}

FONTE: 0 autor.

NOTAS: 1. o asterisco indica a existência de conselho ativo no município.

2. Fundef: Fundo de Manutenção e Desenvolvimento do Ensino Fundamental e de Valorização do Magistério 4

Sobre esse fenômeno destaca-se, em primeiro lugar, que a ampla disseminação no Brasil de alguns conselhos, como é o caso dos conselhos do Fundef, da Alimentação Escolar, da Saúde, da Assistência Social e dos Direitos da Criança, é conseqüência direta de uma legislação superior que não apenas os obriga como vincula a transferência de recursos da União ao seu funcionamento. Celene Tonella (2006) tem razão quando chama a atenção para possíveis conseqüências de estabelecerem-se formatos idênticos de funcionamento para conselhos que operam em realidades tão distintas quanto as que podemos encontrar no interior de um universo composto por mais de cinco

\footnotetext{
${ }^{4}$ Em 2007 o Fundef passou a ser chamado de Fundeb, isto é, Fundo de Manutenção e Desenvolvimento da Educação Básica e de Valorização dos Profissionais da Educação.
} 
mil unidades, como é o caso da federação brasileira. Preocupada com a influência do arcabouço histórico-institucional na conformação dos conselhos, Soraya Côrtes (2005) observa que uma das conseqüências dessa padronização é que a disseminação de conselhos em praticamente todos os municípios do país não garante aos usuários e beneficiários dos serviços públicos uma representação autônoma e consistente em todos os lugares. Tal situação, entretanto, muito pouco tem a ver com o tamanho do município, mas, principalmente, deve-se ao fato de que em algumas localidades a sociedade jamais postulara uma instituição desse tipo e não apresenta o nível de organização necessário para fazer-se representar autônoma e consistentemente nesses espaços.

É possível verificar ainda no Quadro acima que a maioria dos municípios analisados apresenta certo grau de originalidade na instituição de conselhos; ou seja, eles possuem um ou dois conselhos que não são encontrados nos outros. Portanto, ao lado de uma disseminação provocada por determinações superiores, muitos municípios têm criado conselhos por iniciativa própria e segundo circunstâncias que lhes são específicas. Essa observação parece indicar que tanto os grandes como os pequenos municípios - independentemente dos motivos - já incorporaram a criação de conselhos em seu arsenal de estratégias políticas e administrativas.

\section{III.2. Data de fundação}

Como próximo ponto para a análise destacase a data de criação dos conselhos (Gráfico 1). Nesse item observa-se que na região estudada os conselhos aparecem, nitidamente, como um fenômeno recente. Com as exceções registradas do Conselho Municipal de Segurança da cidade de Mal. Cândido Rondon, fundado no ano de 1989, e do Conselho das Relações de Trabalho de São Miguel do Iguaçu, fundado em 1985, todos os outros tiveram origem a partir de 1990, com pico em 1995 causado pela fundação de conselhos de assistência social em cinco dos sete municípios estudados, como consequiência da regulamentação da Política Nacional de Assistência Social.

\section{GRÁFICO 1 - DISTRIBUIÇÃO DA QUANTIDADE DE CONSELHOS POR ANO DE FUNDAÇÃO}

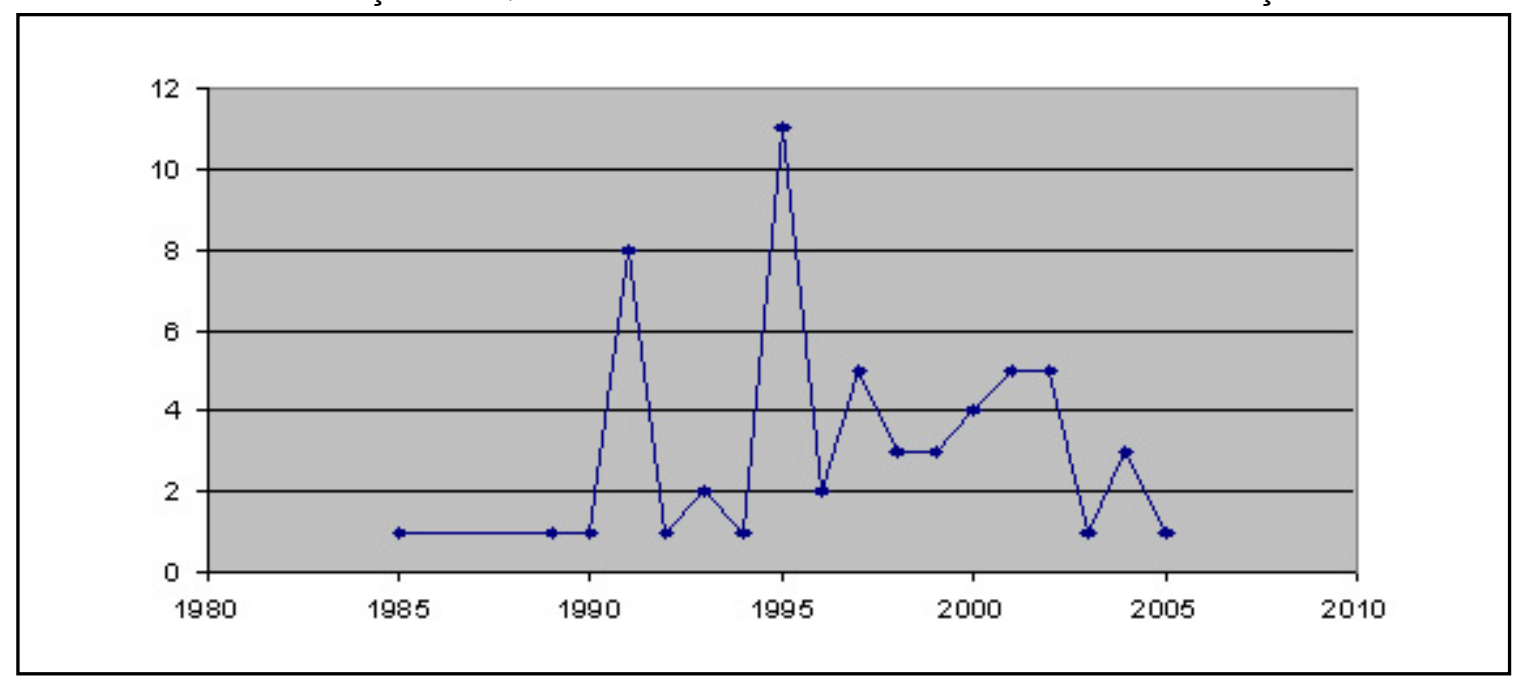

FONTE: 0 autor.

Não resta dúvida de que a década de 1990 foi marcada "pela institucionalização dos conselhos municipais” e que isso ocorreu como conseqüência da vigência da nova Constituição. Como já foi observado, os conselhos transformaram-se no formato institucional assumido por dispositivos presentes no texto da carta de 1988 que estabeleciam a participação da sociedade na gestão e controle das políticas públicas em diversas áreas fun- damentais como saúde, assistência social e educação (SANTOS JR., RIBEIRO \& AZEVEDO, 2004). O reconhecimento da relevância e do impacto adquiridos pelos conselhos no período imediatamente seguinte à promulgação da Constituição, entretanto, não pode induzir conclusões mecânicas. Os conselhos não são apenas a materialização de dispositivos presentes no texto constitucional. É evidente que a nova carta de- 
sempenhou um papel fundamental, induzindo a difusão de conselhos, mas eles decorrem de impulsos participativos presentes na sociedade brasileira antes de e durante o processo constituinte e que, sob muitos pontos de vista, permanecem atuantes mesmo após a regulamentação ocorrida naquelas áreas explicitadas. É o que se depreende dos fatos de algumas dessas experiências antecederem a Constituição e de que, passados mais de 20 anos do início da sua vigência, novos conselhos municipais continuem sendo instituídos em áreas tão distintas quanto imprevistas, como ficou demonstrado no item anterior (Quadro 1).

\section{III.3. A questão da representação nos conselhos}

O quadro a seguir (Quadro 2) informa quais as entidades associativas possuem representação garantida nos conselhos analisados por citação ex- pressa em seus regimentos ou instrumentos legais responsáveis por sua criação. Para a composição desse quadro as citações não foram contabilizadas. Isso significa que algumas categorias ou associações aparecem em documentos de um único conselho e outras em vários. Essa opção decorre do fato de que a intenção, aqui, é construir um quadro abrangente, que indique quais os segmentos da sociedade estão representados nos conselhos, sem questionar qual é o nível de intensidade da participação de cada um deles. Nesse sentido, deve ser observado, também, que no Quadro em referência não foram incluídas categorias cuja representação política é indefinida, como “usuários”, " "prestadores de serviços" e "trabalhadores", comuns nos conselhos das áreas de saúde e assistência social, ou "professores” e "pais de alunos”, típicas dos conselhos do Fundef e da Alimentação Escolar.

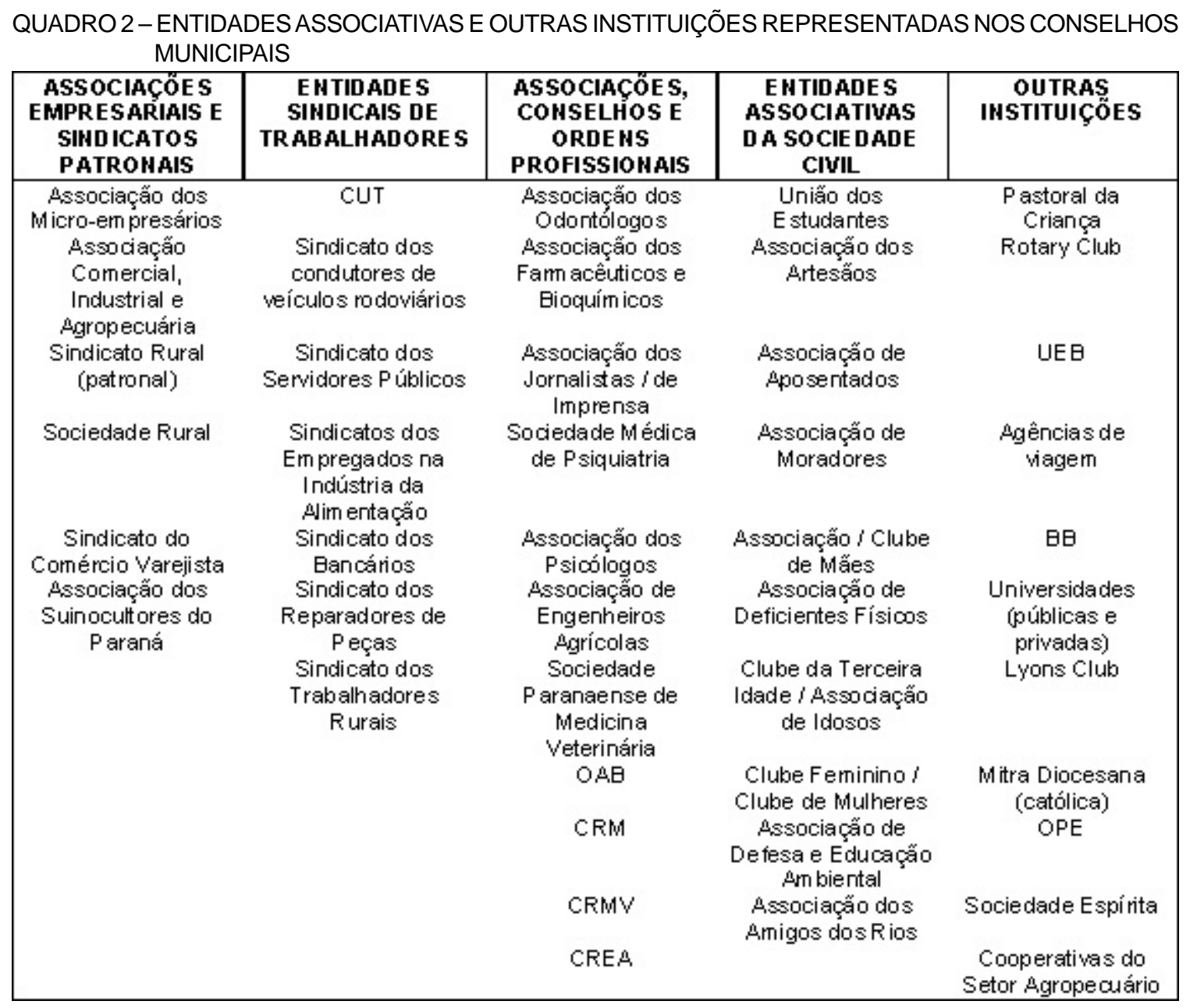

FONTE: o autor.

NOTA: CUT: Central Única dos Trabalhadores; UEB: União dos Escoteiros do Brasil; BB: Banco do Brasil; OAB: Ordem dos Advogados do Brasil; CRM: Conselho Regional de Medicina; OPE: Ordem dos Pastores Evangélicos; CRVM: Conselho Regional de Medicina Veterinária; CREA: Conselho Regional de Engenharia e Arquitetura. 
A relação de segmentos sociais representados nos conselhos estudados pode ser considerada relativamente ampla, sem que isso signifique, contudo, que esses conselhos não apresentem problemas de representação. Tal fato é especialmente importante porque muitas vezes os conselhos municipais são apresentados como instrumentos próprios da democracia direta que, combinados com aqueles do regime representativo, têm como objetivo reduzir o grau da "insuficiência de representação política” que acomete as democracias ${ }^{5}$. Problemas de representação foram detectados por vários estudos, os quais, inclusive, têm sido unânimes em apontar a existência de distorções entre o perfil sociodemográfico dos conselheiros e o da população em geral. Por exemplo, os estudos de Tonella (2004; 2006) sobre os conselhos gestores na região de Maringá, no interior do estado do Paraná, coincidem com aquele conduzido por Santos Jr., Ribeiro e Azevedo (2004) baseado nas regiões metropolitanas de São Paulo, Rio de Janeiro, Belo horizonte e Belém, ambos concluindo que os setores mais pobres e de baixa escolaridade da população, ou seja, exatamente aqueles que constituem o público preferencial das políticas sociais, não encontram representação nos conselhos.

A metodologia aqui adotada fornece algumas informações que podem contribuir para explicar tais distorções. Trabalhando com dados extraídos de regimentos, leis ou decretos que instituem os conselhos, somos colocados diante de determinações legais que condicionam o perfil dos conselheiros. Nesse sentido, mesmo que não se espere uma representação de tipo descritiva, ou seja, que os conselhos constituam um verdadeiro microcosmo, reproduzindo perfeitamente a sociedade representada (MIGUEL, 2003), deve ser observado que o quadro em referência, na coluna "Outras instituições", registra a presença no interior dos conselhos de diversas instituições não-associativas e que, portanto, não representam nada além dos seus interesses particulares. Também é digna de nota a presença de associações comerciais, industriais e agropecuárias, sem a contrapartida de uma representação dos trabalhadores da indústria, do comércio ou da

\footnotetext{
5 Uso aqui a expressão de Miguel (2003).
}

agropecuária, com a exceção dos trabalhadores rurais. Da mesma forma, a coluna "Entidades sindicais de trabalhadores" indica uma baixa freqüência dos sindicatos de trabalhadores nesses espaços, contrastando com a forte presença de categorias liberais ou de profissões de nível superior (advogados, médicos, assistentes sociais, veterinários, engenheiros etc.) registrada nas colunas "Entidades sindicais" e "Associações, conselhos e ordens profissionais". Esses dados, quando comparados com o reduzido número de registros encontrados na coluna "Entidades associativas da sociedade civil” (apenas dez em um total de 58 conselhos analisados), parecem indicar que os conselhos municipais, ainda que sejam considerados novidades no cenário político, não conseguem fugir à lógica corporativista que permeia a prática política no Brasil e reforçam uma participação de tipo regulada, em que se destaca a presença de segmentos profissionais com extensa tradição corporativa, como é o caso de médicos, engenheiros, advogados e suas poderosas organizações.

A representação da diversidade da sociedade civil encontra vazão nas figuras do representante dos "pais de alunos" e dos "usuários”. A imprecisão sobre quem pode, legitimamente, representar usuários de serviços públicos universais tem possibilitado uma representação que, diferenciandose daquela de tipo descritiva, caminha no sentido de uma representação substantiva, em que a legitimidade decorre mais do conteúdo da atividade do representante, identificada com os interesses dos representados, do que de uma autorização formal para a representação (CÔRTES, 2002). Naquela imprecisão, portanto, reside a possibilidade da atuação de setores politicamente mobilizados e movimentos sociais de diversos matizes no interior dos conselhos - com a evidente limitação de que "usuários" e "pais de alunos” são figuras típicas dos conselhos das áreas de saúde, assistência social e educação.

III.4. Forma de escolha do presidente dos conseIhos; periodicidade das reuniões e duração dos mandatos dos conselheiros.

Neste ponto há que se questionar, inicialmente, o grande número de presidentes dos conselhos indicados por Prefeito ou Secretário Municipal, mesmo que esses casos não constituam maioria (tabelas 4 e 5). 
TABELA 4 - FORMA DE ESCOLHA DO PRESIDENTE DOS CONSELHOS

\begin{tabular}{|l|c|c|}
\hline FORMA DE ESCOLHA & $\begin{array}{c}\text { QUANTIDADE DE } \\
\text { CONSELHOS }\end{array}$ & $\%$ \\
\hline Eleiçẫo & 34 & 58,6 \\
Indicaçẫo do poder Executivo (Prefeito ou Secretário) & 18 & 31,1 \\
Indefinido & 6 & 10,3 \\
Total & 58 & 100,0 \\
\hline
\end{tabular}

FONTE: 0 autor.

NOTA: consideramos para esta tabela todos os conselhos em todos os municípios pesquisados.

TABELA 5 - FORMA DE ESCOLHA DO PRESIDENTE DOS CONSELHOS, POR MUNICÍPIO

\begin{tabular}{|l|c|c|c|}
\hline \multirow{2}{*}{ MUNICíPIO } & \multicolumn{3}{|c|}{ FORhA DE ESCOLHA } \\
\cline { 2 - 4 } & ELEIÇÅO & INDICAÇẢO & INDEFINIDO \\
\hline Cascavel & 3 & 2 & - \\
Mal. Cândido Rondon & 3 & 2 & - \\
Ouro Verde do Oeste & 1 & 3 & 1 \\
S. José das Palmeiras & 2 & 1 & 2 \\
S. Miguel do lguaçu & 4 & - & 1 \\
Toledo & 4 & 1 & - \\
Vera Cruz do Oeste & 2 & 2 & $5(14,3 \%)$ \\
Total $(\%)$ & $19(54,3 \%)$ & $11(31,4 \%)$ & 1 \\
\hline
\end{tabular}

FONTE: 0 autor.

NOTA: para esta tabela consideramos apenas os conselhos existentes em todos os municípios pesquisados.

Comparando o comportamento dos diferentes municípios e considerando nesse caso apenas os conselhos existentes em todos os municípios analisados (Saúde, Alimentação Escolar, Fundef, Assistência Social e Direitos da Criança), pode-se ver que a quantidade de conselhos com presidentes escolhidos por eleições ou indicados por Prefeito ou Secretário Municipal é variável, embora apenas um entre eles apresente a maior parte dos presidentes indicados. Esse fato reforça a hipótese formulada por Tótora e Chaia (2004) de que o funcionamento dos conselhos depende da gestão municipal; essa dependência introduz o risco da transformação dos conselhos de instrumento de participação da sociedade na gestão pública em "fonte de legitimação política". Como analisamos aqui documentos legais que instituem formalmente os conselhos e tornam, portanto, suas características fundamentais mais estáveis e menos vulneráveis à ações casuísticas, podemos estender esta hipótese e dizer que o funcionamento dos conselhos depende, também, do perfil do poder Executivo que detém o poder no momento de sua instituição, quando se decide qual é o formato que a instituição apresentará. Não é completamente desnecessário salientar, entretanto, que esta influência será exercida no contexto de uma conjuntura na qual outras forças também estarão em ação.
Assim, o resultado final, ou seja, o desenho institucional de um conselho consolidado em lei é produto de uma determinada correlação de forças que contrapõe o poder Executivo a outras forças organizadas da sociedade.

O grau de interferência do poder Executivo nas atividades dos conselhos é o outro lado do nível de autonomia dos conselhos. Nesse sentido, ao lado da prerrogativa de escolher seus próprios presidentes, a determinação da periodicidade de reuniões, estabelecida em lei ou em regimento interno, pode ser um importante instrumento para evitar que o conselho seja convocado a deliberar apenas de acordo com a conveniência do poder Executivo. É o que acontece com cerca de $90 \%$ dos conselhos pesquisados (Tabela 6).

\begin{tabular}{|c|c|c|}
\hline PERIODICIDADE & N. DE CONSELHOS & $\%$ \\
\hline Mensal & 36 & 62,0 \\
\hline Bimestral & 10 & 17,2 \\
\hline Trimestral & 04 & 7,0 \\
\hline Semestral & 02 & 3,5 \\
\hline Não definida & 06 & 10,3 \\
\hline Total & 58 & 100,0 \\
\hline
\end{tabular}

FONTE: o autor. 
Mesmo que a agenda dos conselhos seja controlada por seus presidentes e que grande parte destes sejam indicados pelos prefeitos, a prática de reuniões periódicas e constantes - desde que elas realmente ocorram, pois alguns estudos indicam que, nesse ponto, nem sempre o regimento é cumprido (IPARDES, 2001) - é fundamental para que eles trilhem o caminho da autonomia. Não se trata, é óbvio, de uma condição suficiente, mas necessária. Ou seja, apenas reuniões periódicas e constantes não garantem que um conselho adquira autonomia, mas, sem dúvida, isso não pode acontecer quando um conselho reúne-se "de vez em quando” ou com freqüência indeterminada.

A periodicidade das reuniões é importante, também, porque na grande maioria dos conselhos o mandato dos conselheiros é de apenas dois anos, o que implica pouco tempo para eles poderem inteirar-se da dinâmica das reuniões, dos processos de construção da agenda, das disputas abertas e veladas no interior do conselho etc., o que torna cada reunião um momento privilegiado de aprendizado. Esse raciocínio não pretende negar a necessidade de "capacitação" dos conselheiros por intermédio de cursos, seminários, fóruns e outros eventos. É certo que o conselheiro tem o direito de conhecer a "teia burocrática" que envolve sua atividade, como sugere Gohn (2001). Mas é certo, também, que “capacitar pressupõe um conjunto de conhecimentos e saberes que conferem aos transmissores um poder" (TÓTORA \& CHAIA, 2004, p. 219), ao contrário do aprendizado que ocorre durante processos nos quais o cidadão aprende a reconhecer os seus interesses e a diferenciá-los dos outros em disputa. É esse tipo de aprendizado que conduz à autonomia.

\section{CONSIDERAÇÕES FINAIS}

Como vimos nos traços acima esboçados, os conselhos municipais estudados nos pequenos municípios do interior, como não poderia deixar de ser, apresentam alguns problemas e algumas contradições na sua formatação que podem reduzir sensivelmente o potencial democratizador dessas instituições. Cabe destacar principalmente que se, por um lado, eles deixam ver representados no seu interior um espectro relativamente amplo de grupos e segmentos sociais, por outro lado essa representação apresenta distorções significativas: ao lado da presença de inúmeras instituições que representam apenas seus próprios interesses e das organizações patronais que centralizam a repre- sentação dos proprietários, destaca-se a presença de segmentos profissionais com sólida e extensa tradição corporativa, como é o caso dos médicos, engenheiros, advogados e seus poderosos conselhos e associações profissionais. Esse não é, entretanto, um problema específico dos pequenos municípios: ele apenas transparece nesses municípios com maior clareza. O fato é que o processo de modernização industrial no Brasil implica, para sua consecução controlada, a organização burocrática da participação política da sociedade por intermédio de organizações corporativas que guardam estreitos vínculos com o Estado, mesmo após a reorganização proporcionada pela Constituição de 1988. Refletindo sobre os conselhos de desenvolvimento rural, Ricardo Abramovay (2001, p. 130) sugere que "talvez o mais importante desafio histórico dos conselhos de desenvolvimento rural, esteja na valorização desta vida associativa no meio rural que não se confunde com as organizações formais como os sindicatos e as cooperativas [...]”. Penso que podemos estender suas reflexões para além do mundo rural e dizer, sem receio de pecar por exagero, que um dos mais importantes desafios históricos dos conselhos gestores de políticas públicas no Brasil está na valorização das formas associativas que não se confundam com as organizações tradicionais, como os sindicatos e as associações profissionais.

Outro grupo de problemas detectados na perspectiva da organização democrática dos conselhos relaciona-se com a forte influência que o poder Executivo pode exercer na sua composição e direção, com a nomeação do Presidente e o conseqüente controle sobre a agenda e sobre a dinâmica de seu funcionamento. A hipótese mais imediata para explicar esse fenômeno remete a um controle de caráter "coronelista” exercido pelos prefeitos dos pequenos municípios sobre a política local. Essa hipótese ignora que a supremacia do poder Executivo diante dos outros poderes na política brasileira é um fenômeno que se pode constatar em todos os níveis de governo e, novamente, apenas aparece com maior clareza nos pequenos municípios do interior. A preocupação, entretanto, dos mandatários locais em exercer controle sobre a atuação dos conselhos pode ser considerada como um indicativo do potencial que estes apresentam: no mínimo eles são suficientes para despertar preocupações da parte daqueles que estão no poder. Isso implica dizer que a 
institucionalização dos conselhos - o que parece ser o mais importante - amplia de fato a arena política, tanto nos grandes como nos pequenos municípios.

Finalmente, algumas palavras devem ser ditas sobre a superação das práticas clientelistas largamente difundidas na política brasileira. O clientelismo é uma prática fundada na desigualdade social e econômica entre atores que se encontram na arena política, em que um apresenta-se em posição de subordinação e dependência por não possuir os meios necessários para garantir a reprodução da sua subsistência e o outro posiciona-se como o detentor do controle sobre os recursos que podem prover esses meios. A clientela não precisa, necessariamente, ser constituída de camponeses, nem os provedores precisam ser “coronéis”. Essa prática pode ser verificada no relacionamento de líderes políticos com suas "bases" nas grandes cidades, até mesmo na relação com movimentos sociais e organizações populares altamente mobilizados. No esboço traçado neste estudo não se identificou nenhuma garantia de que tais práticas podem ser definitivamente bloqueadas pela institucionalização dos conselhos como instância de deliberação ou de controle público. Porém, visto que o acesso a recursos está no centro do problema, à medida que tais instituições caminham para a autonomia, elas podem funcionar como via alternativa de acesso àqueles recursos, tornando-se, por isso, palco de disputa entre os tradicionais mandatários e os segmentos subalternos da sociedade. É o teor dessa disputa que, em última instância, determina a inconstância característica do desempenho dos conselhos em diferentes locais.

Osmir Dombrowski (osmir@unioeste.br) é Doutor em Ciência Política pela Universidade de São Paulo (USP) e Professor Adjunto da Universidade Estadual do Oeste do Paraná (Unioeste).

\section{REFERÊNCIAS BIBLIOGRÁFICAS}

ABRAMOVAY, R. 2001. Conselhos além dos limites. Estudos Avançados, São Paulo, v. 15, n. 43, p. 121-140. Disponível em : http:// www.scielo.br/pdf/ea/v15n43/v15n43a11.pdf. Acesso em : 12.maio.2005.

ALVES, M. M. 1980. A força do povo : democracia participativa em Lajes. São Paulo : Brasiliense.

BIELSCHOWSKY, R. 1995. Pensamento econômico brasileiro : o ciclo ideológico do desenvolvimentismo. $2^{\mathrm{a}}$ ed. Rio de Janeiro : Contraponto.

CARVALHO, J. M. 1997. Mandonismo, coronelismo, clientelismo : uma discussão conceitual. Dados, Rio de Janeiro, v. 40, n. 2, p. 229-250. Disponível em : http:// www.scielo.br/scielo.php?pid=S001152581997000200003\&script=sci_arttext. Acesso em : 15.maio.2008.

CÔRTES, S. M. V. 2002. Participação de usuários nos conselhos municipais de Saúde e de Assistência Social de Porto Alegre. In : PERISSINOTTO, R. M. \& FUKS, M. (orgs.). Democracia : teoria e prática. Rio de Janeiro : Relume-Dumará.
2004. Arcabouço institucional e participação em conselhos municipais de saúde e assistência social. In : SANTOS JR., O. A.; QUEIROZ, L. C. \& AZEVEDO, S. (orgs.). Governança democrática e poder local : a experiência dos conselhos municipais no Brasil. Rio de Janeiro : Revan.

2005. Arcabouço histórico-institucional e a conformação de conselhos municipais de políticas públicas. Educar, Curitiba, n. 25, p. 143174. Disponível em : http:// calvados.c3sl.ufpr.br/ojs2/index.php/educar/ article/viewFile/2243/1875. Acesso em : 28.maio.2006.

DAGNINO, E. 2002. Democracia, teoria e prática : a participação da sociedade civil. In : PERISSINOTTO, R. M. \& FUKS, M. (orgs.). Democracia : teoria e prática. Rio de Janeiro : Relume-Dumará.

DUARTE, N. 1966. A ordem privada e a organização política nacional. $2^{\mathrm{a}}$ ed. São Paulo : Nacional.

GOHN, M. G. 2001. Conselhos gestores e participação sociopolítica. São Paulo : Cortez. 
IBGE. 2004a. Indicadores sociais municipais uma análise dos resultados da amostra do Censo Demográfico 2000. Brasil e grandes regiões. Estudos e Pesquisas - Informação demográfica e socioeconômica, n. 14. Rio de Janeiro : Instituto Brasileiro de Geografia e Estatística. Disponível em : http:// www.ibge.gov.br/home/estatistica/populacao/ censo2000/indicadores_sociais/ism2000.pdf. Acesso em : 15.mar.2008.

2004b. Perfil dos municípios brasileiros gestão pública 2004. Rio de Janeiro : Instituto Brasileiro de Geografia e Estatística. Disponível em : http://www.ibge.gov.br/home/ estatistica/economia/perfilmunic/2004/ default.shtm. Acesso em : 15.mar.2008.

2008. Cidades - informações sobre os municípios brasileiros. Paraná. Rio de Janeiro : Instituto Brasileiro de Geografia e Estatística. Disponível em : http://www.ibge.gov.br/ cidadesat/default.php. Acesso em : 15.mar.2008.

IPARDES. 2001. Caracterização dos conselhos municipais de Desenvolvimento Rural do Paraná : síntese dos principais resultados da pesquisa de campo. Curitiba : Instituto Paranaense de Desenvolvimento Econômico e Social.

MIGUEL, L. F. 2003. Representação política em 3-D : elementos para uma teoria ampliada da representação política. Revista Brasileira de Ciências Sociais, São Paulo, v. 18, n. 51, p. 123-140. Disponível em : http://www.scielo.br/ pdf/rbcsoc/v18n51/15989.pdf. Acesso em : 18.maio. 2006

OLIVEIRA VIANNA, F. J. 1987. Instituições políticas brasileiras. V. II. Belo Horizonte : Itatiaia.

SANTOS JR., O. A.; AZEVEDO, S. \& RIBEIRO, L. C. Q. 2004. Democracia e gestão local : a experiência dos conselhos municipais no Brasil. In : SANTOS JR., O. A.; QUEIROZ, L. C. \& AZEVEDO, S. (orgs.). Governança democrática e poder local : a experiência dos conselhos municipais no Brasil. Rio de Janeiro : Revan.

SOUZA, C. 2002. Governos e sociedades locais em contextos de desigualdades e de descentralização. Ciência \& Saúde Coletiva, Rio de Janeiro, v. 7, n. 3, p. 431-442. Disponível em : http://www.scielo.br/pdf/csc/v7n3/ 13023.pdf. Acesso em : 3.maio.2006.

2004. Governos locais e gestão de políticas sociais universais. São Paulo em Perspectiva, São Paulo, v. 18, n. 2, p. 27-41. Disponível em : http://www.scielo.br/pdf/spp/v18n2/ a04v18n2.pdf. Acesso em : 15.set.2006.

TEIXEIRA, A. C. C. 2006. O orçamento participativo em pequenos municípios rurais : contextos, condições de implementação e formatos de experiência. Belo Horizonte : Projeto Democracia Participativa. Disponível em http:/ /democraciaparticipativa.org/files/ AnaClaudiaOor\%E7amentoparticipativoem pequenosmunic\% EDpiosrurais.pdf. Acesso em : 13.fev.2006.

TONELLA, C. 2004. Conselhos municipais de políticas públicas na região de Maringá. In : FUKS, M.; PERISSINOTTO, R. M. \& SOUZA, N. R. (orgs.). Democracia e participação: os conselhos gestores do Paraná. Curitiba : UFPR.

2006. Poder local e políticas públicas : o papel dos conselhos gestores. Maringá : UEM.

TÓTORA, S. \& CHAIA, V. 2004. Conselhos municipais e a institucionalização da participação política : a Região Metropolitana de São Paulo. In : SANTOS JR., O. A.; QUEIROZ, L. C. \& AZEVEDO, S. (orgs.). Governança democrática e poder local : a experiência dos conselhos municipais no Brasil. Rio de Janeiro : Revan. 


\section{LOCAL POWER, HEGEMONY AND DISPUTES: MUNICIPAL COUNCILS IN SMALL MUNICIPALITIES}

\section{Osmir Dombrowski}

This article discusses the implantation of municipal councils in small Brazilian municipalities in Brazil, characteristically representing over half of the country's existing municipalities. Our hypothesis is that small municipalities can have a veritable "microscopic" function, revealing phenomena that, albeit universal, tend to get lost within the greater complexity of political relations in large cities. The work is divided into two parts. In the first one, we make a brief commentary on the process of consolidation and dissemination of a bias that is a frequent part of studies on rural Brazil and affects analyses of local power: we argue that theory should not relegate small municipalities to the role of places that have been left behind, lacking in civic consciousness and characterized by low degrees of democratic political culture. In the second part, we present some empirical data from research on councils in the Western region of the state of Paraná which suggest that, in spite of evident limitations, these institutions may function as an alternative route of access to political resources and for this very reason become a scenario of conflict. In the last instance, it is the nature of this dispute that determines the characteristic inconstancy in the way in which councils in different places are able to perform.

KEYWORDS: local power; municipal councils; clientelism; participation.

\section{POUVOIR LOCAL, HÉGÉMONIE ET DISPUTE : LES CONSEILS MUNICIPAUX DANS LES VILLES DE PROVINCE}

\section{Osmir Dombrowski}

L'article aborde l'institution des conseils municipaux dans les petites villes de province, qui représentent plus de la moitié des villes du Brésil. L'article fait l'hypothèse que les petites villes peuvent fonctionner comme des vrais «microscopes », révélant des phénomènes qui, bien qu'universels, tendent à s'effacer dans la complexité des relations politiques dans les grandes villes. Le travail est structuré sur deux parties : dans la première, on présente un bref commentaire sur le processus de consolidation et de dissémination d'un préjugé qui figure dans les études du Brésil rural et atteint l'analyse du pouvoir local ; dans la seconde, on présente quelques données empiriques dressées dans une recherche auprès des conseils de la région Ouest de l'état du Paraná, qui suggèrent que, malgré les limitations, ces intitutions peuvent fonctionner comme une voie alternative d'accès à des recours politiques, et qui deviennent donc des espaces de dispute : c'est la teneur de cette dispute qui détermine en substance l'inconsistance caractéristique de la performance des conseils dans différentes localités.

MOTS-CLÉS: pouvoir local ; conseils municipaux ; clientélisme politique ; participation 